\section{A new roadmap for drug development for Alzheimer's disease}

\author{
Robert E. Becker, Nigel H. Greig, Ezio Giacobini, Lon S. Schneider and \\ Luigi Ferrucci
}

\begin{abstract}
An article in Nature Reviews Drug Discovery (Nature Rev. Drug Discov. 11, 657-660; 2012) ${ }^{1}$ reported that three prevention trials
\end{abstract} (known as API, DIAN and A4) in patients with asymptomatic Alzheimer's disease (AD) hope, with biomarker and cognitive changes, to validate the amyloid hypothesis and set the stage for AD drug approvals. A response (Nature Rev. Drug Discov. 12, 324; 2013) ${ }^{2}$ endorsed the plans in this earlier report.

Here, we question the wisdom of this step for these trials and another proposed study (known as DSBI) (TABLE 1). As currently designed, we consider that $\mathrm{AD}$ drug development trials have four important deficiencies. First, without the addition of aims to test specific mechanistic hypotheses that are able to explain the conditions necessary to modify the course of $\mathrm{AD}$, these clinical trials will not advance our knowledge of $\mathrm{AD}$ neuropathologies and their roles in progression to symptomatic AD. Second, knowledge of how the timing of neuropathologies may affect the successful use of agents that target the 42 -amino-acid form of the amyloid- $\beta$ peptide $\left(A \beta_{42}\right)$ or other $\mathrm{AD}$ drugs will not advance. Third, a potentially useful drug may be abandoned owing to lack of clinical efficacy. Fourth, drug effects on symptoms may be misinterpreted as evidence for disease modification.

\section{Background}

Lack of mechanistic grounding for currently proposed AD clinical trials. There are several issues that might confound the currently proposed AD clinical trials. First, both $\mathrm{A} \beta_{42}$-related and phosphorylated-tau (p-tau)-related neuropathologies are well established a decade or more before $\mathrm{AD}$ is clinically diagnosed ${ }^{1-3}$. Second, concentrations in the brain of $A \beta_{42}$ and its oligomers and neurofibrillary tangles correlate with - but do not predict - the severity, progression or diagnosis of dementia ${ }^{3,4}$. The planned trials initiate treatments before clinical AD onset, but without timing treatment so that it specifically targets any irreversible neuropathology that later triggers clinical dementia ${ }^{5}$. They do not exclude or investigate these issues and therefore risk starting treatment after a self-sustaining pathology is established.

Furthermore, clinical AD is associated with other disease conditions, such as cerebral amyloid angiopathy and other cerebrovascular pathologies. These or other accompanying conditions have the potential to precipitate patients with familial or sporadic $\mathrm{AD}$ into clinical dementia. Age, co-morbidity, vascular pathologies, insulin resistance, genetic, environmental, biochemical or cognitive reserve factors may be necessary for clinical expression of dementia. If such possibilities are not considered, the planned trials of the anti-A $\beta_{42}$ drugs may be confounded, undermining their utility. For example, the patients with familial AD involved in the DIAN trial ${ }^{6}$ inevitably develop AD pathology and progress to clinical $\mathrm{AD}$, which provides a unique opportunity to understand the roles of $A \beta_{42}$ and self-sustaining pathologies without involving subjects who do not progress on to dementia. However, if other confounding factors are not accounted for, its utility will be compromised.

Elusive clinical efficacy. Other than immediately before and following the clinical diagnosis of mild cognitive impairment (MCI), there has been no evidence reported so far to support the ameloriation of cognitive deficits as a demonstration of clinical efficacy for proposed therapeutic interventions for AD. Indeed, emerging evidence supports the view that 'clinically silent' AD neuropathologies accumulate to cause clinically observable MCI and AD decades later ${ }^{1-3}$. Consequently, unless patients are followed up for 10 years or more, it seems unlikely that clinical efficacy of the anti-A $\beta_{42}$ agents or other interventions being tested in currently proposed clinical trials will be seen.

In the proposed clinical trials involving asymptomatic patients, any observed cognitive changes (or lack of cognitive changes) could not be definitively ascribed to effects of the intervention on $\mathrm{AD}$-relevant neuropathologies without additional evidence. For example, cognitive enhancement may occur without affecting AD-relevant neuropathologies and important neuropathological benefits may occur without cognitive effects. This could lead to erroneous decisions to claim (or not claim) effects on disease progression and to progress (or terminate) the further development of the compounds being studied.

\section{A new roadmap}

Drug development for AD has failed to significantly improve on earlier drug treatments, despite impressive advances in our understanding of the cellular and molecular biology of the disease. In our view, this is partly because clinical trials so far have focused on efficacy and not on the rigorous testing of the putative mechanisms of disease and the impact of the drugs tested on these mechanisms.

Known mechanisms that increase the levels of $A \beta_{42}$ in $\mathrm{AD}$ include the following: increased synthesis of the amyloid precursor protein; altered $\gamma$-secretase activities; and reduced clearance of $A \beta_{42}$. Subjects in the API, DIAN and DSBI trials have known genetic factors that potentially affect the increased synthesis of the amyloid precursor protein and/or altered $\gamma$-secretase activities. In the A4 trial, subjects predominantly have genetic or other factors affecting clearance of $\mathrm{A} \beta_{42}$. However, none of the trials are timing the drug intervention on the basis of prior investigations of the onset of possible irreversible $A \beta_{42}$ accumulation or $A \beta_{42}$ induction of a neuropathology critical to progression into clinical dementia. Nor are the trials designed to specifically test the different timings of possible critical $A \beta_{42}$ accumulations or inductions. Because of the pathological effects of p-tau on neurons, controlling only $A \beta_{42}$ concentrations even a decade or more before clinical $\mathrm{AD}$ may have no effect on $\mathrm{AD}$ progession regardless of the various factors that are thought to underlie the development of AD in the different trial populations (TABLE 1).

We propose that investigators give priority to the development of a molecular mechanistic theory for $\mathrm{AD}$ that will distinguish disease by the pathogenesis underlying the final common pathway to clinical AD. In addition, this theory will discriminate the specific neuropathological target or targets to be tested and how they will be tested for clinical relevance. For example, the current amyloid hypothesis of $\mathrm{AD}$ does not identify a specific pathogenic target or targets responsible for clinical $\mathrm{AD}$, or differentiate roles for $\mathrm{A} \beta_{42}, \mathrm{~A} \beta_{42}$ oligomers or $\mathrm{A} \beta_{42}$ amyloid concentrations and multiple other factors and the interactions among these. The amyloid hypothesis is also not able to predict the 


\begin{tabular}{|c|c|c|c|c|c|c|}
\hline $\begin{array}{l}\text { Sponsoring } \\
\text { group }\end{array}$ & $\begin{array}{l}\text { Subjects (number } \\
\text { proposed) }\end{array}$ & $\begin{array}{l}\text { Special } \\
\text { conditions }\end{array}$ & $\begin{array}{l}\text { Rationale for subject } \\
\text { selection }\end{array}$ & $\begin{array}{l}\text { Drug } \\
\text { intervention }\end{array}$ & $\begin{array}{l}\text { Trial } \\
\text { duration }\end{array}$ & Outcome variable(s) \\
\hline $\begin{array}{l}\text { Alzheimer's } \\
\text { Prevention } \\
\text { Initiative (API)9,10 }\end{array}$ & $\begin{array}{l}\text { Asymptomatic } \\
\text { subjects with } \\
\text { mutations in PS1 } \\
\text { (100 drug; } 100 \\
\text { placebo) }\end{array}$ & $\begin{array}{l}\text { PS1-positive } \\
\text { subjects within } \\
10 \text { years before } \\
\text { apparent } \\
\text { cognitive decline }\end{array}$ & $\begin{array}{l}\text { Excess } A \beta_{42} \text { levels } \\
\text { predispose to } \\
\text { early-onset } A D\end{array}$ & Crenezumab & 5 years & $\begin{array}{l}\text { PET-fibrillar A } \beta \text {, PET-FDG, } \\
\text { structural MRI and clinical } \\
\text { end point biomarkers } \\
\text { accepted as indicators } \\
\text { of AD progression and } \\
\text { an untested composite } \\
\text { of five cognitive tests not } \\
\text { specified }^{9,10}\end{array}$ \\
\hline $\begin{array}{l}\text { Dominantly } \\
\text { Inherited } \\
\text { Alzheimer } \\
\text { Network (DIAN) }^{6}\end{array}$ & $\begin{array}{l}\text { Asymptomatic } \\
\text { subjects at-risk } \\
\text { for familial AD } \\
\text { (mutations in APP, } \\
\text { PS1 and PS2) (160) }\end{array}$ & $\begin{array}{l}\text { Subjects within } \\
15 \text { years of } \\
\text { predicted AD } \\
\text { onset }\end{array}$ & $\begin{array}{l}\text { Confirmed family } \\
\text { pedigree for autosomal } \\
\text { dominant AD }\end{array}$ & $\begin{array}{l}\text { Solanezumab } \\
\text { and } \\
\text { gantenerumab }\end{array}$ & 5 years & $\begin{array}{l}\text { Neuropathological } \\
\text { biomarkers to validate } \\
\text { target effects of drug } \\
\text { interventions and an } \\
\text { undisclosed cognitive end } \\
\text { point }^{6}\end{array}$ \\
\hline $\begin{array}{l}\text { Down Syndrome } \\
\text { Biomarker } \\
\text { Initiative' (DSBI) }{ }^{12}\end{array}$ & $\begin{array}{l}\text { Subjects with } \\
\text { Down's syndrome } \\
(12)\end{array}$ & APP trisomy & $\begin{array}{l}\text { Development of brain } \\
\text { amyloid plaques and } \\
\text { neurofibriallary tangles } \\
\text { by age } 30 \text { years and } \\
\text { increased lifetime risk } \\
\text { (75\%) for AD }\end{array}$ & Not specified ${ }^{12}$ & 3 years & Not specified ${ }^{12}$ \\
\hline
\end{tabular}

ADCS-PACC, Alzheimer's Disease Cooperative Study-Preclinical Alzheimer's Cognitive Composite; APP, amyloid precursor protein; FDG, fludeoxyglucose; MRI, magnetic resonance imaging; PET, positron emission tomography; PS, presenilin. ${ }^{\star}$ The concern for all of these studies (discussed in the main text) is that $\mathrm{A} \beta$-induced phosphorylated-tau and/or other self-sustaining cascades may have already been initiated, and as currently designed they miss the opportunity to test these or other mechanistic hypotheses.

effects from drugs used to alter $\mathrm{A} \beta_{42}$ targets or define the timing of interventions. With long durations between interventions and disease onset, at least three of the currently proposed AD clinical trials - API, DIAN and DSBI - are well positioned to take on these tasks of turning $\mathrm{AD}$ drug development away from an overly exclusive focus on product development and onto the investigation and validation of a mechanistic theory of AD.

Consistent with this effort, and to avoid the mistaken termination of drugs for lack of clinical efficacy, we recommend that investigators in the current trials pursue evidence for mechanistic efficacy as rigorously as possible rather than overly invest in clinical efficacy as end points. Trials will be regarded as scientifically successful if they demonstrate both drug safety and, with biomarkers grounded in refined and tested $\mathrm{AD}$ mechanistic theory, neuropathologically significant, not merely statistically significant, reductions in pre-specified, theoretically justified, $A \beta_{42}$-related or other neuropathologies. Preferred end points would be a return of the targeted neuropathology to levels found in non-at-risk AD subjects. Using biomarkers with documented mechanistic implications, currently proposed trials can test the molecular mechanisms that are able to explain both the lack of efficacy for persons at-risk of AD but still not symptomatic and the grounds for expecting the subjects to progress to clinical AD.

In summary, we suggest that for $\mathrm{AD}$ drug development to become more soundly scientifically grounded, researchers need to give priority to the development of a molecular theory of disease that will be systematically tested and refined in clinical trials ${ }^{7}$. AD clinical trials continue to be initiated with little or no robust data relating to the mechanism of action leading to disease progression. Most problematic, the planned trials initiate treatments prior to clinical $\mathrm{AD}$ onset, but without timing that specifically targets any irreversible neuropathology that later triggers clinical dementia ${ }^{8}$. Scientifically and ethically, mechanisms of drug action are optimally identified, confirmed and characterized in preclinical studies before progressing to clinical trials. The abandonment of anti-A $\beta_{42}$ drugs and pursuit of clinical efficacy for new targets will not fix the problems we discuss. As a first step we propose modifications of currently planned and future AD clinical trials to provide maximum support for the advance of theory and for continued research with compounds with potential uses as pharmacological probes of disease mechanisms or drug candidates in future AD clinical trials.

Robert E. Becker, M.D., C.M., is the President of Aristea Translational Medicine, 5011 Mountain View Road \#63, Carrabassett Valley, Maine O4947, USA, and a Clinical Consultant in the Drug Design and Development Section, Translational Gerontology Branch, Intramural Research Program, National Institute on Aging,

National Institutes of Health, Baltimore, Maryland 21224, USA.

Nigel H. Greig, Ph.D., is a Senior Investigator in the Drug Design and Development Section, Translational Gerontology Branch, Intramural Research Program, National Institute on Aging, National Institutes of Health, Baltimore Maryland 21224, USA.

Ezio Giacobini, M.D., Ph.D., is a professor in the Department of Internal Medicine, Rehabilitation, and Geriatrics, University of Geneva, Medical School, University Hospitals of Geneva, Thonex-Geneva, Switzerland

Lon S. Schneider, M.D., M.S., is a professor in the Departments of Psychiatry, Neurology, and Gerontology, Keck School of Medicine, University of Southern California, Los Angeles, California 90033, USA. 
Luigi Ferrucci, M.D., Ph.D., is the Scientific Director of the Intramural Research Program, National Institute on Aging, National Institutes of Health, Baltimore, Maryland 21224, USA.

Correspondence to R.E.B. e-mail: rebecker@AristeaTM.com doi: 10.1038/nrd3842-c2 Published online 20 December 2013

1. Mullard, A. Sting of Alzheimer's failures offset by upcoming prevention trials. Nature Rev. Drug Discov. 11, 657-660 (2012)

2. Aisen, P. S., Vellas, B. \& Hampel, H. Moving towards early clinical trials for amyloid-targeted therapy in Alzheimer's disease. Nature Rev. Drug Discov. 12, 324 (2013).

3. Buchhave, P. et al. Cerebrospinal fluid levels of $\beta$-amyloid $1-42$, but not of tau, are fully changed already 5 to 10 years before the onset of Alzheimer dementia. Arch. Gen. Psychiatry. 69, 98-106 (2012).

4. Rodrigue, K. M. et al. $\beta$-Amyloid burden in healthy aging: regional distribution and cognitive consequences. Neurology 78, 387-395 (2012)

5. Pike, K. E. et al. Cognition and $\beta$-amyloid in preclinical Alzheimer's disease: data from the AIBL study. Neuropsychologia. 49, 2384-2390 (2011).

6. Morris, J. C. et al. Developing an international network for Alzheimer's research: the Dominantly Inherited Alzheimer Network. Clin. Invest. 2 975-984 (2010)
7. Becker, R. E. \& Greig, N. H. Neuropsychiatric clinical trials: lost in translation. Sci. Transl. Med. 2, 61 rv6 (2010).

8. Vellas, B. et al. Designing drug trials for Alzheimer's disease: what we have learned from the release of the phase III antibody trials: a report from the EU/US/ CTAD Task Force. Alzheimers Dement. 9, 438-444 (2013).

9. Reiman, E. M. Langbaum, J. B \& Tariot, P. N . Alzheimer's prevention initiative: a proposal to evaluate presymptomatic treatments as quickly as possible. Biomark. Med. 4, 3-14 (2010).

10. Reiman, E. M. et al. Alzheimer's Prevention Initiative: a plan to accelerate the evaluation of presymptomatic treatments. J. Alzheimers Dis. 26 (Suppl. 3), 321-329 (2011)

11. Vaughn, P. NIH-supported Alzheimer's studies to focus on innovative treatments. National Institute on Aging website [online], http://www.nia.nih.gov/ newsroom/2013/01/nih-supported-alzheimers-studiesfocus-innovative-treatments\#sthash NaXdACa5. dpufhttp://www.nia.nih.gov/newsroom/2013/01/ nih-supported-alzheimers-studies-focus-innovativetreatments. (2013).

12. Ness, S. et al. Down's syndrome and Alzheimer's disease: towards secondary prevention. Nature Rev. Drug Discov. 11, 655-656 (2012).

Competing interests statement

The authors declare competing interests: see Web version for details. 